\title{
Study on Social Stability Risk Detection of Large Hydraulic Project Construction Based on Social Vulnerability Evaluation
}

\author{
WU Aihua ${ }^{1,3}$,Zhang Changzheng ${ }^{1,2,3(\bowtie)}$,Zhijie Ma ${ }^{4}$ \\ ${ }^{1}$ Business School, Hohai University, Nanjing, China \\ \{wahvip@139.com,zcz@hhu.edu.cn\} \\ ${ }^{2}$ Columbia Water Center, New York, U.S.A; \\ ${ }^{3}$ Hohai Industrial Economics Institute, Nanjing, China; \\ ${ }^{4}$ China Institute of Water Resource and Hydropower Research (IWHR), Beijing, China \\ $\{$ mazj@jwhr.com $\}$
}

\begin{abstract}
Reducing vulnerability of social system is the foundation of social stability, if the social system becomes more and more vulnerable, then the social stability risk is greater, on the contrary, it is smaller, which put forward higher request for developing social risk detection platform. Risk detection is a kind of typical fuzzy pattern problem, a technology based on vulnerability evaluation is used for social stability risk. This paper analyzes the reasons of social vulnerability in the large hydraulic project construction area from three dimensions which are characteristic function of social risk exposure, social sensitivity and social adaptability capability, and builts the vulnerability evaluation model and risk detection index system, using entropy method to calculate the detection index weight. The paper finds that Wanzhou social vulnerability (social stability risk) present reduced year by year from 1999 to 2011, and the change caused by the enhancement of social adaptability capability, not by the fall of social system risk. The finding proves that social economic development, social security and public opinion promote the Social adaptability capability in Wanzhou.
\end{abstract}

Keywords: Large hydraulic project construction, Social vulnerability, Risk detection.

\section{$1 \quad$ Introduction}

Since New China is established, around 86 thousand large and middle scale hydraulic projects and hydropower projects have been built, including for 482 large reservoirs and hydropower projects. These projects have played an important role in promoting the economic construction and social development. However, the construction of these projects have also resulted in a quantity of engineering migration about 24,000 thousand persons, therefore the covering population due to the migration movement and arrangement is rather huge. It markedly affects the social stability of the construction areas. The migration due to hydraulic projects is always the most disputed problem in the international hydropower development, and also is an international difficult problem not been solved up to now (Michael M. Cernea,1987,1993). The migration due to hydraulic projects and hydropower project is subject to the nature of non-voluntary migration, and the migration is usually involved with a large population of a whole village or a whole town and even a whole county, such as, for the "Three Gorges Project" of China, the migration quantity is totally about 1270000 persons (up to the bottom of 2009), and the submerged cities and towns are about 129 pieces. This fully indicates that the construction of large hydraulic projects will inevitably influence the adjustment, recovery and reconstruction of a complex system function of "Population - Resources Environment - Society - Economy", which is a typical complex system reconstruction.

Except for the complexity, openness, self-organization and non-linear of the complex system, Wei Qi(2004) ${ }^{[1]}$ thought that it also has a basic property of vulnerability and the vulnerability is the root of system malfunction. The vulnerability study of system is initially come from the study of biogeocenose and natural disaster, which is first raised out by Timmerman P.(1981) ${ }^{[2]}$. This concept has been used for many study fields such as, Tao Tao $(1999)^{[3]}$ used this concept in the water resources system, and Lind $(1995)^{[4]}$ used it in the engineering management. What's more, with the continuous appearance of global environmental problems, the vulnerability study has become a hot spot and front edge of sustainable development. Su Fei $(2008)^{[5]}$ thought that the vulnerability of social system is caused by the sensibility to the various perturbations from the inside and outside of 
social system and the abilities short of relying to the unfavorable perturbations, which makes the social system easily progress to the discontinuity. Adger $(2000)^{[6]}$ thought that the vulnerability of social system means the quantity ability of the social replying to the disaster and environmental risk as the social comes under the impact and pressure from the disaster and environmental risk. And Qian Xuesheng(1988)thought that the social system was a large, special and complex system, and the stability of the system found expression in the sustainable development of the social stability and development. Therefore, the standpoint of this text is that the vulnerability of social system means the social damage degree exposed to the risks and abilities replying to the risks, as well as the change degree of the social stability as the social system under the perturbations, i.e., means a change degree that the social system is changed from the stability into the unstable and discontinuous. In this changing period, the social system is more frangible, more far away from its stability, and then the stable risk of this society is much greater. The construction of major hydraulic project will cause the reconstruction of social system, and unavoidably bring the social stability in the construction area to the various risks, so the social stable risk of major hydraulic project is a social risk caused by the typical social system stability of the construction area disturbed by the external perturbations, as well as the social vulnerability in the construction area results in the society short of the ability replying to the external perturbations. This text will analyze the causes of social system vulnerability in the major hydraulic project, and based on the analysis to the risks of social system and the abilities for the social system replying to the risks to evaluate the social vulnerability, and then using the degree of social vulnerability to judge the risk levels of social stability.

\section{Characteristic function for the vulnerability of social system of major hydraulic project}

\subsection{Characteristic function modeling techniques of vulnerability social system of major hydraulic project}

On modeling characteristic function of risk detection, this paper adopts the analysis method mentioned in reference[7]. The model is mainly divided into three models, which are risk carrier, risk content and risk context. Vulnerability risk can be illustrated with the triple $V=\{$ VCarrier, VContent, VContext $\}$, where V is Vulnerability risk Item; VCarrier means risk carrier; VContent represents risk content; VContext stands for risk contexts.

- VCarrier $=<$ risk carrier $>:\{$ the style of carrier, the relation of risk, the social impact of Carrier [risk gent, risk time, risk event]\};

- VContent can be described of what the risk content contains;

- VContext can be described as: VContext $=\{\mathrm{D} 1, \mathrm{D} 2, \cdots, \mathrm{DN}\}$.

\subsection{Social risk exposure dimensionality}

The major hydraulic project is different from the general hydraulic project, because it has the following properties: large construction scale, high technical complex, long construction period and facing complex problems. Because of that, it has a far-reaching affection to the social and economic development, ecological environment, polity and military affairs of the construction area and even a country, and has a "broad interface" with the social contact face in the construction area, so the risk exposure degree of major hydraulic project is higher than the general hydraulic project.

The construction scale of major hydraulic project means that the project construction necessarily brings an expropriation, removing and population migration. Larger scale means higher social risk exposure. The expropriation and population migration are the focus of social conflicts, and also the collective impersonation of social risk exposure of major hydraulic project. In general, the expropriation and removing will cause the social risks of benefit conflicts and benefit rearrangement, while the social risks from the population migration are much more serious.

Large-scale hydraulic project is a complex systematic project. The technical difficulties met in its construction and operation are much more than that of general-purpose hydraulic projects, and how to effectively solve such technical difficulties is the basis for the effective and safe operation of 
large-scale hydraulic project.

The long construction period of large-scale hydraulic project makes the social contradictions become more serious and the exposure to social risks is higher than before. According to the relation between the risk and the time, the risk is the function of time. Therefore, the longer construction period leads to the greater possibility to expose to social risks.

There are many complex problems in the construction of large-scale hydraulic project, which indicates the impact of large-scale hydraulic project on society, economy and environment is also complex with the labyrinth of relationships.

\subsection{Social sensitivity dimensionality}

Social system sensitivity relates to some special emotions of the society in specified areas on some issues, such as the folk-custom emotion, cultural emotion, community emotion, social life style, mode of production and traditional view and awareness, etc, which is incurred by social changes arising from such interference factors. It also involves the intensity of original social contradiction and social prominent problems by the interference factors. The social system vulnerability triggered by large-scale hydraulic project, to a certain degree, depends on social system sensitivity in the construction area. For example, human-land conflict in the reservoir area of Three Gorges has been always in a prominent position. The arable land per capita for emigrants reduced to $0.58 \mathrm{mu}$ due to the construction of "Three Gorges Project", of which the arable land per capital in Wanzhou reduced from $1.9 \mathrm{mu}$ in 1992 to $0.69 \mathrm{mu}$, and the arable land per capital for farmers in some areas surrounding the reservoir area was only $0.4 \mathrm{mu}$. This further intensified the human-land conflict and caused the changes in population structure. For instance, the complicated psychical factors occur after the transformation of farmers' life style and mode of production caused by the urbanization. Since enterprises in the reservoir area of Three Gorges are highly dependent on special geography of such area, a lot of enterprises go bankrupt and cease the production due to the migration, consequently leading to changes in the employment structure and income incurred by the "industry hollowness". Thus, large-scale hydraulic project can directly increase social system risks on one hand and on the other hand, indirectly conduct the impact of it on social vulnerability.

\subsection{Response ability dimensionality of social system}

The Social adaptability capability is an integral part of social system vulnerability. The social vulnerability in the construction area of large-scale hydraulic project depends on the risk response ability of social system to a certain degree. If the impact of the construction of such work is within the range of social system response capacity, the social system vulnerability remains unchanged and social system is stable on the whole. Conversely, risks to stability of social system tend to increase. The social system response ability is based on the social economy and social development, in which the local social equity, social security, social order, social control and public opinion have significant impacts on the social adaptability capability. In this regard, the analysis on the social vulnerability in the construction area of large-scale hydraulic project from the view of the response ability can analyze the response abilities of local social equity, social security, social order, social control and public opinions. As the social equity is the basis for social stability, it plays a big role in mitigating the personal discontented mood and social contradiction, reducing personal resistance to society, as well as weakening the impact of the construction of large-scale hydraulic project on social vulnerability to a certain degree. The improvement of social security system is able to mitigate the impact of large-scale hydraulic project on changes in the social structure, while the resettlement and compensation standards centering on emigrants are particularly important with the social security imperfect. The social sequence refers to social conditions under which the social dynamics achieve an orderly balance. The migration caused by the construction of large-scale hydraulic project makes an impact on the social sequence. If the original social sequence remains stable, the social system has a strong ability to respond to the impact arising from the construction of such work. The social control is the key component of social management by the government and social organizations, and also the important embodiment for the promotion of social stability by the government and social organization. The high-level social control over the construction area of large-scale hydraulic project plays an important role in promoting the solution of social contradiction arising there from by the government and social organization. 


\section{Risk assessment method of social stability to large scale hydraulic project construction based on the social vulnerability}

\subsection{Social vulnerability assessment model based on the large-scale hydraulic project construction}

Based on the vulnerability assessment model raised by IPCC and the generalized vulnerability model proposed by Shi Peijun(2002) ${ }^{[9]}$, according to the response of social system to the large-scale hydraulic project construction, the social vulnerability based on the large-scale hydraulic project construction is considered in two aspects herein, that is the social system risk and the adaptability of social system, among which, the social system risk means the social risk exposure degree and the comprehensive response of social system sensibility to the large-scale hydraulic project construction. The social vulnerability assessment model established on the large-scale hydraulic project construction is as follows:

$$
V_{s}^{*}=\left(V_{s f}+V_{s v}\right) / V_{c}
$$

among which, $V_{s}^{*}$ means the social vulnerability in the large-scale hydraulic project construction area, $\mathrm{V}_{\mathrm{sf}}+\mathrm{V}_{\mathrm{sv}}$ indicates the social system risk in the large-scale hydraulic project construction area, while $\mathrm{V}_{\mathrm{c}}$ shows the social system adaptability of large-scale hydraulic project construction area.

$$
V_{s f}+V_{s v}=W_{1} \sum_{i=1}^{n 1} w_{i} * r_{i j}+W_{2} \sum_{k=1}^{\mathrm{n} 2} w_{k} * r_{k l}
$$

In which, $\mathrm{W}_{1}$ and $\mathrm{W}_{2}$ indicate the social risk exposure degree and the influence weighting of social system sensibility to the social system stability respectively; while $r_{i j}=(i=1,2, \ldots, n 1 ; j=1,2, \ldots, m 1)$ and $r_{k l}(k=1,2, \ldots, n 2 ; l=1,2, \ldots, m 2)$ indicate the matrix of determined values.

$$
V_{c}=\sum_{h=1}^{n 3} w_{h} * r_{h p}
$$

$w_{h}$ and $r_{h p}(h=1,2, \ldots, n 3 ; p=1,2, \ldots, m 3)$ are respectively the weighting of assessment index of social system adaptability in the large-scale hydraulic project construction areas and the matrix of determined values.

\subsection{Vulnerability index system of social system in the large-scale hydraulic project construction areas}

Through analyzing the vulnerability formation causes of social system in the large-scale hydraulic project construction areas, we understand that the large-scale hydraulic project construction directly causes the migration risk, social dispute, economic risk and unemployment risk on one hand as well as changes the population structure, industry structure, employment structure, income and the like of existing social system indirectly through conduction factors; while the social system adaptability is primarily influenced by the economic development, social security, social equality, social order and social public sentiment. Pursuant to the principles of scientificity, purposiveness and operability of index selection, the text, based on the previous studies (Niu Wenyuan, 2001 ${ }^{[9]}$;Song Linfei, $1998^{[10]}, 1999^{[11]}$,etc.) on the social stability, in combination with the experiences of experts, filters and determines the assessment index of social system vulnerability in the large-scale hydraulic project construction areas and evaluates the social system vulnerability in the large-scale hydraulic project construction areas for judging the risk of social stability. For the assessment index system of social system vulnerability in the large-scale hydraulic project construction areas, see Table -1

Table 1. Index system of social system vulnerability in the large-scale hydraulic project construction areas 


\begin{tabular}{|c|c|c|c|c|}
\hline & Factor & Index & Mark & Expression \\
\hline \multirow{8}{*}{$\begin{array}{l}\text { Social } \\
\text { system } \\
\text { risk in } \\
\text { the } \\
\text { construc } \\
\text { tion area } \\
(\mathrm{Vs}+\mathrm{v})\end{array}$} & \multirow{4}{*}{$\begin{array}{l}\text { Social risk exposure } \\
\text { degree of large-scale } \\
\text { hydraulic project } \\
\text { construction (S) }\end{array}$} & Migration risk & $\mathrm{R}$ & Migration population/Area population \\
\hline & & Social dispute & Cs & $\begin{array}{c}\text { Industry hollowing (percentage of loss } \\
\text { in enterprise) }\end{array}$ \\
\hline & & Economic risk & $\mathrm{Ct}$ & $\begin{array}{c}\text { Composite index of economic } \\
\text { efficiency for enterprises }\end{array}$ \\
\hline & & Unemployment risk & $\mathrm{U}$ & Unemployment rate \\
\hline & \multirow{4}{*}{$\begin{array}{l}\text { Social sensibility in the } \\
\text { construction area }(\mathrm{V})\end{array}$} & Population structure & $\mathrm{D}$ & Proportion of urban population \\
\hline & & Industry structure & $\mathrm{I}$ & Proportion of tertiary industry \\
\hline & & $\begin{array}{l}\text { Employment } \\
\text { structure }\end{array}$ & Ey & $\begin{array}{c}\text { Employed persons in the secondary } \\
\text { and tertiary industries / the total } \\
\text { population }\end{array}$ \\
\hline & & Income changes & $\mathrm{Ea}$ & Urban and rural income growth rates \\
\hline \multirow{6}{*}{$\begin{array}{l}\text { Social } \\
\text { system } \\
\text { adaptabi } \\
\text { lity in } \\
\text { the } \\
\text { construc } \\
\text { tion area } \\
(\mathrm{Vc})\end{array}$} & \multirow{6}{*}{$\begin{array}{l}\text { Social adaptability in } \\
\text { the construction area } \\
\text { (C) }\end{array}$} & $\begin{array}{c}\text { Economic } \\
\text { development }\end{array}$ & Ec & Per capita GDP \\
\hline & & Social security & $S$ & Social security contribution rate \\
\hline & & Social equality & $\mathrm{Eq}$ & Urban and rural income ratio \\
\hline & & Social order & Od & $\begin{array}{c}\text { Number of criminal cases/ten } \\
\text { thousand persons }\end{array}$ \\
\hline & & Social control & $\mathrm{G}$ & Per capita expenditure \\
\hline & & $\begin{array}{c}\text { Social public } \\
\text { sentiment }\end{array}$ & $\mathrm{Op}$ & Public safety index \\
\hline
\end{tabular}

\subsection{Determine the weighting based on the entropy method}

Because the social system vulnerability is influenced by various factors, and the influences from the factors to the social vulnerability are changed with time, such makes just using the experts' subjective comments for the evaluation must influence the objectivity of the results. However, the entropy can reflect the disorder degree of the system. The lower the entropy, the lower the disorder degree of the system, the lower the influence to the system stability, contrarily, becomes higher. The social vulnerability or social risk usually roots in the disordered change of some social factors. For the calculation steps on determining weighting by entropy method, see references ${ }^{[12]}$. The entropy weight $\mathrm{W}$ for assessment index is:

$$
W=\left(w_{i}\right)_{1 \times n}=\left(\frac{1-H_{i}}{n-\sum_{i=1}^{n} H_{i}}\right)_{1 \times n}
$$

Of which, $\sum w_{i}=1, H_{i}$ is the entropy of assessment index.

\section{Evaluating the social system vulnerability and social stability risk of Wanzhou in Three Gorges Reservoir}

Since the construction of the Three Gorges Project, Wanzhou as the backland of the Three Gorges migration, totally 263 thousand people have migrated dynamically, accounting for one fifth of the number in Three Gorges Reservoir, one fourth of the number in Chongqing Reservior. Although they push the local economy ahead, the constant project migration and immigration investment do influence the social stability constantly. The text, based on the data reported in 1999-2011 Wanzhou Statistics Bulletin on Social and Economic Development, evaluates 13 years' Wanzhou social system vulnerability for assessing the influence of large-scale hydraulic project to social stability.

The results on the vulnerability evaluation of social system in Wanzhou within the construction area of Three Gorges Project are shown in the Tab.2. The results show that: 1)during 2000 and 2003 of Three Gorges hydraulic project construction, the vulnerability index of social system in Wanzhou is 2.097, 2.419,2.631 and 3.014 respectively and far higher than other investigation years. Fig. 2 shows that the vulnerability index of social system in Wanzhou rigion has been in the change range of [0,2] since a sharp decline of 2003. (2)the risk index of social system in Wanzhou presented the increasing trend of "Increase - Decrease - Increase", risk index of 1999 is 0.216 , and the risk 
index of social system reached 0.566 in 2006 , then its index decrease year by year, is 0.381 in 2006 .However, the risk of social stability in Wanzhou is constantly raised after 2007, which indicates that second ecological migration implemented by Chongqing city after 2007 has increased the risk of social system in Wanzhou, and the exposure of social risk resulted in by the construction of Three Gorges Project and implementation of subsequent work has the continuity, for example, the social risks exposed in 2010 and 2011 are in highest position.(3) the Social adaptability capability in Wanzhou has increased constantly, the response ability evaluation index of which has raised from 0.26 in 1999 to 0.89 in 2011, and the size of social adaptability capability has a direct influence on the control ability of social system against social risk. Tab.2 shows that the social system risks in 2003 and 2009 are at the same level $(\mathrm{Vs}+\mathrm{v}(2003)=0.516$, Vs+v(2009)=0.550), but the social vulnerability index $(\mathrm{Vs}=0.996)$ in 2009 decreased by 3 times compared to the vulnerability index $(\mathrm{Vs}=2.45)$ in 2003 , which indicates that strong response ability plays an important role in maintaining social stability.

Table 2. Results on the vulnerability evaluation of social system in Wanzhou region within the construction area of Three Gorges Project

\begin{tabular}{|c|c|c|c|c|c|}
\hline \multirow[b]{2}{*}{ Year } & \multirow{2}{*}{$\begin{array}{c}\text { vulnerabilit } \\
\text { y of social } \\
\text { system (Vs) }\end{array}$} & \multicolumn{3}{|c|}{ Social system risks $(\mathrm{Vs}+\mathrm{v})$} & \multirow{2}{*}{$\begin{array}{l}\text { Social adaptability } \\
\text { capability }(\mathrm{Vc})\end{array}$} \\
\hline & & & $\begin{array}{c}\text { Risk exposure Extent } \\
(\mathrm{S} * 0.69)\end{array}$ & $\begin{array}{l}\text { Social system sensitivity } \\
(\mathrm{V} * 0.31)\end{array}$ & \\
\hline 1999 & 0.841 & 0.216 & 0.258 & 0.122 & 0.257 \\
\hline 2000 & 2.097 & 0.339 & 0.380 & 0.247 & 0.162 \\
\hline 2001 & 2.419 & 0.372 & 0.412 & 0.281 & 0.154 \\
\hline 2002 & 2.631 & 0.566 & 0.633 & 0.415 & 0.215 \\
\hline 2003 & 3.014 & 0.516 & 0.558 & 0.419 & 0.171 \\
\hline 2004 & 1.701 & 0.463 & 0.514 & 0.346 & 0.272 \\
\hline 2005 & 1.232 & 0.441 & 0.392 & 0.553 & 0.358 \\
\hline 2006 & 1.032 & 0.381 & 0.281 & 0.607 & 0.369 \\
\hline 2007 & 1.051 & 0.450 & 0.367 & 0.638 & 0.428 \\
\hline 2008 & 1.178 & 0.528 & 0.513 & 0.562 & 0.448 \\
\hline 2009 & 0.996 & 0.550 & 0.544 & 0.562 & 0.552 \\
\hline 2010 & 0.959 & 0.646 & 0.611 & 0.724 & 0.674 \\
\hline 2011 & 0.776 & 0.687 & 0.656 & 0.757 & 0.886 \\
\hline
\end{tabular}

According to the evaluation result of social system vulnerability in Wanzhou, the risk reduction of social stability in Wanzhou is caused by the increase in Social adaptability capability of Wanzhou social system. Based on the calculation by the entropy method, the index weight of Social adaptability capability is $w=(0.193,0.195,0.113,0.144,0.1685,0.1865)$, from which we can see that economic development, social security and social public opinion are main contributors to raise the social adaptability capability. Statistical Bulletin of Social and Economic Development of Wanzhou in 2011 shows that in 2011 the safety index of Wanzhou people had been increased to $96.3 \%$ and the composite scores of people's sense of safety have reached up to $90 \%$ for seven years.

\section{Summary}

With the rise of the concept of green hydraulic projects, the sustainable development of the construction of major hydraulic projects becomes the hot spot of current research. It is required that the construction of major hydraulic projects shall not only drive the development of local economy but also promote the social harmony. The vulnerability of social system is directly relative to the stability of social system. The smaller the vulnerability of social system is, the lower the risk of instability of social system is, whereas the risk of instability of social system can become higher. The conclusion shows that the risk of social system caused by major hydraulic projects is inevitable, but for maintaining the social stability, the construction of social adaptability capability is very important. So during the implementation of construction, the local society needs to accelerate the development of local economy, improve the local social security system, narrow the gap between the rich and the poor, and create a good social safety environment to increase the people's 
satisfaction. The above-mentioned things are very important for decreasing the impact of the vulnerability of social system, reducing the risk of social instability and maintaining the development of social stability.

\section{Acknowledgement}

Funds for this research was provided by the International S\&T Cooperation Program of China(2012DFA60830).

\section{References}

1. Wei Qi, Jin Hongzhang,et al, Research on complex system based on brittleness,Journal of Systems Engineering, vol.19,pp.326-328,(2004).

2. Timmerman P.Vulnerability, Resilience and the Collapse of Society: A Review of Models and Possible Climatic Applications. Toronto, Canada: Institute for Environmental Studies, University of Toronto, (1981)

3. Tao Tao, Ji Changming, A Study and Application of Reliability, Resilience.Vulnerability of Water Resources System,Journal of Hydroelectric Engineering, vol.66,pp.103-109,(1999).

4. Lind N C, Measure of vulnerability and damage tolerance, Reliability Engineering \& System Safety,vol.48, pp.1-6,(1995).

5. Su Fei, Zhang Pingyu. Frangibility Assessment of Fuxin Social System, Reskurces\&Industries, vol.10,pp.1-5, (2008)

6. Adger, W. N, Social and Ecological Resilience: Are They Related? Progress in Human Geography, vol.24,pp.347-364,(2000).

7. PAN Xuwei, GU Xinjian, QIU Yuanfu, et al. Knowledge modeling techniques for knowledge management .Computer Integrated Manufacturing Systems, 9 (7):518 - 521(2003)

8. Shi Peijun, Theory on disaster science and disaster dynamics,Journal of Natural Disasters, vol.11,pp.1-9,(2002).

9. Niu Wenyuan. The Social Physics and the Warning System of China's Social Stability,Bulletin of the Chinese Academy of Sciences,vol.1,pp.15-20,(2001).

10. Song Linfei. Evaluations and Countermeasures of Social Development, Social Sciences in Nanjing,vol.110, pp.19-28,(1998).

11. Song Linfei.The design and operation of Social Risk forewarning System in China, Journal of Southeast University,vol.1,pp.69-76,(1999).

12. Meng Xianmeng and Shu Longcang, Modified DRASTIC model for groundwater vulnerability assessment based on entropy weight,Journal of Hydraulic Engineering, vol.38,pp.94-99,(2007)

13. M. Millie Kwan, P.Balasubramanian. Knowledge-scope: managing knowledge in context. Decision Support Systems , 35 (4) : 467 - 486(2003).

14. PAN Xuwei, GU Xinjian, Wang Zhengcheng, et al. Methods \& key technologies of knowledge management integrating context. Computer Integrated Manufacturing Systems, 5(2007)

15. Ahh H J, Lee H J, e al . Utilizing knowledge context in virtual collaborative work. Decision Support Systems, 39 (4):56325821(2005) 